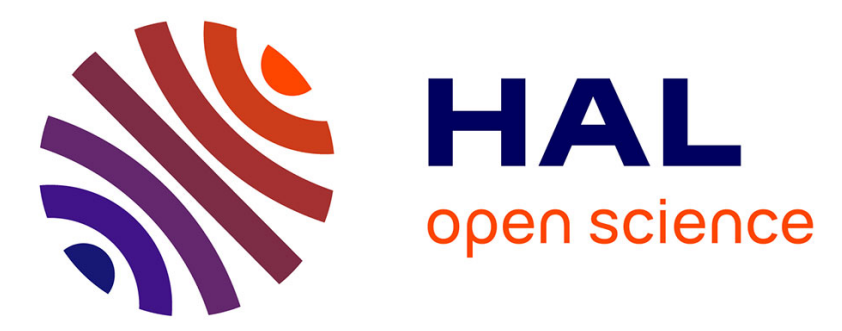

\title{
Prognosis of fuel cell degradation under different applications using wavelet analysis and nonlinear autoregressive exogenous neural network
}

Kui Chen, Salah Laghrouche, Abdesslem Djerdir

\section{- To cite this version:}

Kui Chen, Salah Laghrouche, Abdesslem Djerdir. Prognosis of fuel cell degradation under different applications using wavelet analysis and nonlinear autoregressive exogenous neural network. Renewable Energy, 2021, 179, pp.802 - 814. hal-03549359

\section{HAL Id: hal-03549359 \\ https://hal.science/hal-03549359}

Submitted on 31 Jan 2022

HAL is a multi-disciplinary open access archive for the deposit and dissemination of scientific research documents, whether they are published or not. The documents may come from teaching and research institutions in France or abroad, or from public or private research centers.
L'archive ouverte pluridisciplinaire HAL, est destinée au dépôt et à la diffusion de documents scientifiques de niveau recherche, publiés ou non, émanant des établissements d'enseignement et de recherche français ou étrangers, des laboratoires publics ou privés. 


\title{
Prognosis of fuel cell degradation under different applications using wavelet analysis and nonlinear autoregressive exogenous neural network
}

\author{
Kui Chen, Salah Laghrouche, Abdesslem Djerdir
}

FEMTO-ST, UMR CNRS 6174, and FCLAB, FR CNRS 3539, Université Bourgogne

Franche-Comté, Belfort/UTBM 90000, France 


\section{Introduction}

With environmental protection and increasing energy demand, sustainable green energy is regarded as the main direction of future energy development [1]. The fuel cell directly converts the chemical energy of the fuel into electricity without being restricted by the Carnot cycle [2]. The fuel cell has the advantages of high specific energy, high energy conversion efficiency, no pollution, low noise, many types of fuel, etc [3]. The fuel cell is widely used in cogeneration, power plants, fuel cell electric vehicles, portable power systems, distributed generation, and other fields [4]. Due to the fact that its distinguishing features include low operating temperature, lower pressure ranges, small size, and no chemical hazards to the human body, Proton Exchange Membrane Fuel Cell (PEMFC) has received high attention from the government, industry, and academia [5]. Currently, PEMFC is regarded as the most likely candidate for transportation and other mobile applications [6]. PEMFC can avoid some battery problems, such as the use of pollutant materials and long charging time [7]. However, durability and cost seriously affect the large-scale commercial application of PEMFC [8]. The degradation of carbon support and Platinum (Pt) nanoparticles will cause the reduction in the performance of PEMFC [9]. The maximum service life of PEMFC under transportation conditions is around $3000 \mathrm{~h}$, while the expected life of PEMFC is at least $5000 \mathrm{~h}$ for commercial transportation applications [10]. Prognostics and health management can predict the degradation of PEMFC and provide an appropriate maintenance plan to reduce the cost and improve the durability of PEMFC [11]. Therefore, the degradation prognosis is very important for the operation and maintenance of PEMFC [12].

The degradation of PEMFC is caused by the degradation of its main components [13]. The main components of PEMFC are bipolar plates, Gas Diffusion Layers (GDL), electrodes, catalysts, and proton exchange membranes. In the long-term operation of PEMFC, these components will experience different degradations [14]. The bipolar plates undergo corrosion, fractures, and deformation. The GDL undergoes structural changes, porosity loss, and hydrophobicity loss. The electrodes and catalysts undergo Pt dissolution, Pt agglomeration, Pt oxidation, and carbon corrosion. The proton exchange membranes undergo decomposition, creep, fatigue, and hot-dot. The degradation of PEMFC usually causes the output voltage to drop, the output power to decrease, the internal resistance to increase, etc [15]. Therefore, the output voltage, output power, and internal resistance are often selected to 
represent the degradation state of PEMFC [16]. In this paper, the output voltage is selected as a degradation indicator of PEMFC because it has been measured to monitor the PEMFC performance.

The prognosis methods of PEMFC are usually divided into 3 categories: model-driven methods, data-driven methods, and hybrid methods [17]. The model-driven methods make the degradation prognosis of PEMFC based on the empirical or semi-empirical degradation model of PEMFC [18]. The degradation trends are simulated through the empirical or semi-empirical degradation model of PEMFC. Three empirical degradation models combined with particle filter are proposed to forecast the degradation and Remaining Useful Life (RUL) of PEMFC [19]. The semi-empirical degradation model combined with the extended Kalman filter is presented to make the degradation prognosis of PEMFC [20]. The Gaussian degradation model combined with an unscented particle filter is developed to make the state of health estimation and RUL prognosis for PEMFC [21].

The PEMFC is a complex, multivariable, and strongly coupled dynamic nonlinear system. The degradation of PEMFC involves the multi-scale (nanometer scale, cell scale, and system scale) and multi-material (carbon fibers, metal, Pt, and Nafion membrane). It is difficult to build the accurate mathematical degradation model of PEMFC because its degradation mechanism is not fully known [22].

The data-driven methods make the degradation prognosis of PEMFC by learning the degradation trend from recorded aging data based on artificial neural network and fuzzy system [23]. The echo state network is proposed to estimate the performance degradation and RUL for PEMFC [24]. The long short-term memory recurrent neural network is applied to predict the degradation and remaining life of PEMFC [25]. The self-adaptive relevance vector machine method is developed to predict the performance degradation of PEMFC [26]. The adaptive neuro-fuzzy inference system method is proposed to forecast degradation in PEMFC [27].

The hybrid methods integrate the advantages of model-driven methods and data-driven methods to make the degradation prognosis of PEMFC [28]. The hybrid method based on three empirical degradation models and the least square support vector machine method is presented to make the degradation and RUL prognosis for PEMFC [29]. The autoregressive and moving average model integrated the time delay neural network is developed to predict the performance degradation of PEMFC [30]. A semi-empirical degradation model integrated the automatic machine learning algorithm is proposed 
to estimate the degradation trend and forecast the RUL for PEMFC [31]. Compared with model-driven methods and data-driven methods, the hybrid methods require the most computation.

The degradation prognosis of PEMFC in most literature studies consider the influence of the historical state, and rarely consider the impact of operating conditions on degradation prognosis. However, the operating conditions have a great influence on the performance of PEMFC [32]. Water flooding in the bipolar plates and membrane electrode assembly can cause gas starvation and may accelerate the corrosion of bipolar plates, electrodes, catalysts, GDL, and membrane [33]. Dehydration of membrane causes high membrane resistance, tearing, and cracking [34]. When gas starvation occurs at the cathode, it will cause the coalescence of the catalyst [35]. When gas starvation occurs at the anode, it will cause carbon support corrosion [35]. Gas starvation may cause the change of electrode thickness, uneven current and voltage distribution, porous structure collapse, and reverse polarity [36]. The temperature has a certain effect on water saturation pressure and membrane hydration [37]. The temperature will affect the water distribution, gas distribution, and chemical reactions, which cause hot spots in the membrane and accelerate the decay of the catalyst [38]. Frequently changing load brings the challenges for water management, thermal management, and gas management, which may cause gas starvation, water flooding, dehydration, hot spot, etc [39]. The start-stop process causes the increase of resistance, high-load operating conditions may accelerate the dissolution of $\mathrm{Pt}$, and rated operating condition leads to a decrease in the electrochemically active area [40]. The historical state and operating conditions including the load current, relative humidity, temperature, and hydrogen pressure are considered by Nonlinear Autoregressive Exogenous Neural Network (NARX) in this paper. NARX is a recurrent dynamic neural network, which has good dynamic characteristics and anti-interference ability in the nonlinear problems of time series prediction.

The degradation of PEMFC includes global degradation trend (irreversible degradation phenomena) and recovery phenomena [41]. The global degradation trend refers to the irreversible loss of PEMFC performance as the PEMFC runs for a long time [42]. The global degradation trend is caused by the degradation of bipolar plates, electrodes, catalysts, gas diffusion layers, and membranes. Recovery phenomena refer to a certain degree recovery performance of PEMFC, when the PEMFC undergoes stop/start, characteristic test, or large changes in operating conditions [43]. For example, when the 
gas supply is sufficient, the PEMFC performance recovers after gas starvation is improved [44]. Recovery phenomena are the transient process during the degradation of PEMFC. Most of the previous prognosis methods only focused on the global degradation trend, while both global degradation trend and recovery phenomena are considered by wavelet analysis in this paper.

Wavelet analysis is an effective time-frequency analysis method. It has the ability to characterize signal local information in time-frequency domain, and is widely used in image compression, signal processing, and information extraction.

The existing prognosis methods rarely use directly raw experimental data to predict the degradation of PEMFC. Because the raw experimental data of PEMFC includes complex fluctuations and recovery phenomena. The raw experimental data of PEMFC in different applications is directly used to predict the degradation in this paper.

Considering the historical state, operating conditions, and different degradation phenomena, this paper presents the degradation prognosis method based on wavelet analysis and NARX for PEMFC operated under different applications. The main contributions are summarized as follows:

1. The proposed prognosis method makes degradation prediction of PEMFC based on the raw experimental data.

2. The NARX, which considers the historical state and exogenous inputs (load current, relative humidity, temperature, and hydrogen pressure), is applied to the degradation prognosis of PEMFC operated under different applications.

3. The global degradation trend and recovery phenomena of PEMFC are analyzed by wavelet analysis, which can effectively improve the accuracy of the degradation prognosis of PEMFC.

4. Experimental results show that this presented method is robust and can be applied to the degradation prognosis of PEMFC in different applications.

In Section 2, the durability tests of PEMFC operated under different applications are presented. Section 3 proposes the degradation prognosis of PEMFC based on NARX and W-NARX. Section 4 presents the validation of the method on the basis of experimental results. Moreover, these results are compared with NARX and different learning data. Section 5 provides Conclusions. 


\section{Durability tests of PEMFC operated under different applica- tions}

\subsection{Durability test of PEMFC in FCHEV operated under real conditions}

The durability test of PEMFC is made in Fuel Cell Hybrid Electric Vehicle (FCHEV) operated under real conditions. The MOBYPOST project has developed ten FCHEVs (Fig. 1) to complete commercial mail delivery tasks on the real road [45]. PEMFC and lithium batteries provide power for FCHEV. Integrating lithium batteries into FCHEV can prevent PEMFC from frequently starting and shutting down, which reduces the PEMFC degradation and increases its lifetime [46]. The main parameter of PEMFC in FCHEV operated under real conditions is shown in Table 1. In order to control and monitor the PEMFC in FCHEV, the operating conditions including load current, voltage, relative humidity, temperature, hydrogen pressure, and state of charge of the hydrogen tank and battery are measured by FCHEV electronic control unit every second. PEMFC adopts the open cathode type with natural humidification. In order to avoid flooding, regular purge is conducted in the hydrogen circuit. The stop/start of PEMFC that greatly changes the distribution of water, gas, and heat in the PEMFC stack causes the recovery phenomena.

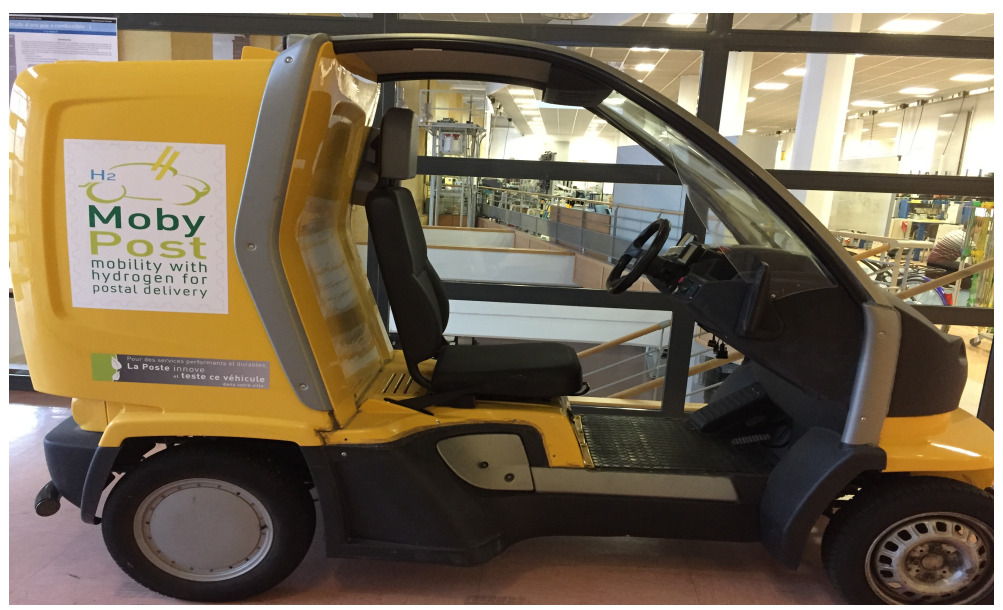

Figure 1: MOBYPOST fuel cell hybrid electric vehicle

\subsection{Durability test of PEMFC operated under quasi-dynamic load current}

The durability test of PEMFC operated under a quasi-dynamic load current is made on the power test platform of FCLAB, as shown in Fig. 2. The 
Table 1: The operating conditions of PEMFC in FCHEV operated under real conditions

\begin{tabular}{|c|c|}
\hline Parameter & Value \\
\hline PEMFC weight & $2.7 \mathrm{~kg}$ \\
\hline Number of cells & 40 \\
\hline Active area & $100 \mathrm{~cm}^{2}$ \\
\hline PEMFC maximum power & $1 \mathrm{~kW}$ \\
\hline PEMFC rated current & $34 \mathrm{~A}$ \\
\hline PEMFC rated voltage & $31 \mathrm{~V}$ \\
\hline Relative humidity & $35 \%-78 \%$ \\
\hline Temperature & $50{ }^{\circ} \mathrm{C}$ \\
\hline Hydrogen pressure & $0.6 \mathrm{bar}$ \\
\hline
\end{tabular}

quasi-dynamic load current is a constant current of $70 \mathrm{~A}$ plus a ripple current of $7 \mathrm{~A}$. The main parameter of PEMFC operated under the quasi-dynamic load current is shown in Table 2, more detailed descriptions of the PEMFC can be found in [47]. In order to control and monitor the PEMFC performance, operating conditions including load current, single cell and stack voltage, relative humidity, temperature, gas flow, air pressure, and hydrogen pressure are measured every half minute. In order to characterize the health status of the PEMFC, the Electrochemical Impedance Spectroscopy (EIS) and polarization curve tests are made approximately weekly ( 0 h, 35 h, $182 \mathrm{~h}, 343 \mathrm{~h}$, and $515 \mathrm{~h}$ ). The characteristic test that greatly changes the distribution of water, gas and heat in the PEMFC stack causes the recovery phenomena.

\subsection{Durability test of PEMFC operated under constant load current}

The durability test of PEMFC operated under constant load current is made on the test platform of FCLAB (Fig. 2). The constant load current is a constant current of $70 \mathrm{~A}$. The main parameter of PEMFC operated under constant load current is shown in Table 3. The operating conditions including load current, single cell and stack voltage, relative humidity, temperature, gas flow, air pressure, and hydrogen pressure are also measured every half minute. the EIS and polarization curve tests are also made approximately weekly (0 h, 48 h, 185 h, 348 h, 515 h, 658 h, and 823 h). After each characteristic test, the recovery phenomena of PEMFC are found. 


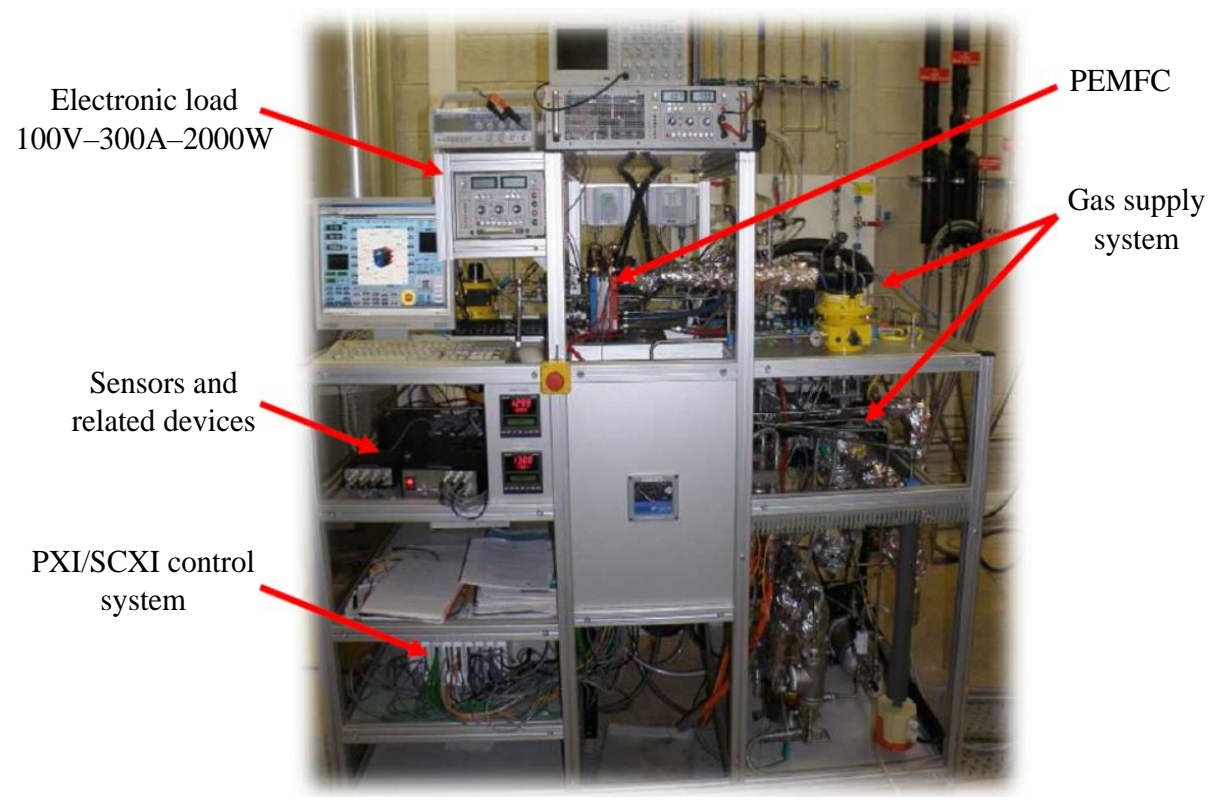

Figure 2: The durability test of PEMFC in power test platform of FCLAB

Table 2: The main parameter of PEMFC operated under the quasi-dynamic load current

\begin{tabular}{|c|c|}
\hline Parameter & Value \\
\hline Number of cells & 5 \\
\hline Membrane thickness & $25 \mu \mathrm{m}$ \\
\hline GDL thickness & $415 \mu \mathrm{m}$ \\
\hline Active area & $100 \mathrm{~cm}^{2}$ \\
\hline PEMFC current & $70 \mathrm{~A}$ with $7 \mathrm{~A}$ ripple \\
\hline Relative humidity & $52 \%$ \\
\hline Temperature & $54{ }^{\circ} \mathrm{C}$ \\
\hline Hydrogen pressure & $1.3 \mathrm{bar}$ \\
\hline
\end{tabular}


Table 3: The main parameter of PEMFC operated under constant load current

\begin{tabular}{|c|c|}
\hline Parameter & Value \\
\hline Number of cells & 5 \\
\hline Membrane thickness & $25 \mu \mathrm{m}$ \\
\hline GDL thickness & $415 \mu \mathrm{m}$ \\
\hline Active area & $100 \mathrm{~cm}^{2}$ \\
\hline PEMFC current & $70 \mathrm{~A}$ \\
\hline Relative humidity & $50 \%$ \\
\hline Temperature & $54^{\circ} \mathrm{C}$ \\
\hline Hydrogen pressure & $1.3 \mathrm{bar}$ \\
\hline
\end{tabular}

\section{PEMFC prognosis method}

\subsection{Prognosis of PEMFC based on NARX}

NARX combines the nonlinear mapping ability of the artificial neural network and the time series concept of the dynamic autoregressive model to solve the problem of time series prognosis [48]. NARX, which takes into account the historical state and exogenous input (operating conditions), is very suitable for the prognosis of PEMFC. The basic structure of NARX is shown in Figure 3.

As shown in Fig. 3, the NARX consists of an input layer, a hidden layer, and an output layer. $X$ represents operating conditions that include load current, relative humidity, temperature, and hydrogen pressure. $Y$ represents the output voltage of the PEMFC. $Y(t)$ is the historical state of PEMFC, $Y(t+1)$ is the prognosis state. $d$ is the maximum delay, $w$ is the weight, $b$ is the threshold. $f_{1}$ and $f_{2}$ are activation functions of hidden layer and output layer, respectively.

The prognosis of PEMFC based on NARX is defined as the following equation.

$$
Y(t+1)=f[Y(t), \cdots, Y(t-d+1), X(t), \cdots, X(t-d+1)]
$$

The hidden layer output is obtained by equation 2 . 


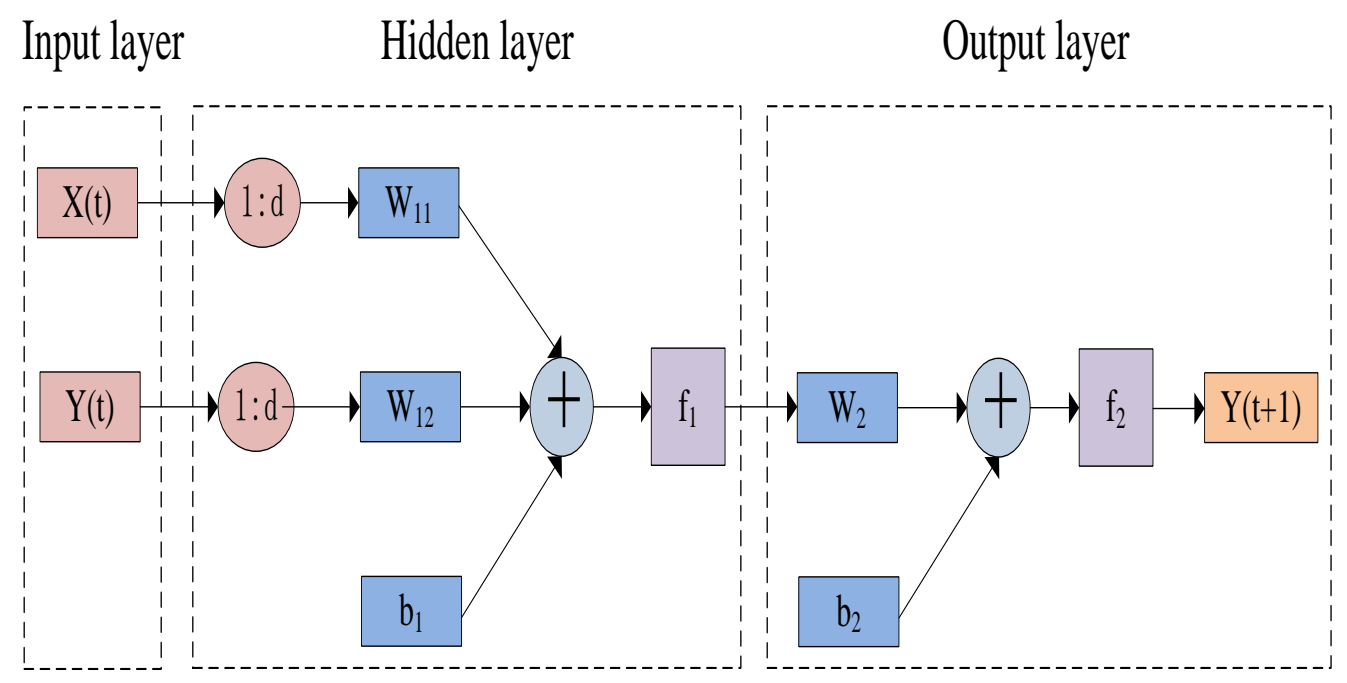

Figure 3: Basic structure of nonlinear autoregressive exogenous neural network

$$
h_{i}=f_{1}\left[\sum_{1}^{d} W_{11} X(t)+\sum_{1}^{d} W_{12} Y(t)+b_{1}\right], i=1, \cdots, L
$$

where $h_{i}$ is the output of the i-th neuron in the hidden layer, and $L$ is the number of neurons in the hidden layer.

The output layer output is obtained by equation 3 .

$$
o_{j}=f_{2}\left[\sum_{1}^{L} W_{2} h(i)+b_{2}\right], j=1, \cdots, m
$$

where $o_{j}$ is the output of the $\mathrm{j}$-th neuron in the output layer, and $m$ is the number of neurons in the output layer.

The biggest difference between the NARX and the general BP neural network is that state delay is added in the NARX. The historical state of PEMFC is considered by the state delay [49]. The parameters of weight and threshold for NARX are trained and adjusted in consideration of operating conditions and the historical state. Therefore, the NARX is considered to apply in the prognosis of PEMFC that greatly affected by operating conditions and the historical state. 


\subsection{Prognosis of PEMFC based on NARX and wavelet analysis}

Wavelet analysis decomposes time series signals through muti-resolution analysis. The multi-resolution analysis is the theoretical basis for signal decomposition and reconstruction under wavelet basis [50]. For any measurement signal, the muti-resolution analysis can decompose it into detail part and low frequency part, and then further decompose the low frequency part, which can be repeated to any scale. The decomposition process can be expressed by equation 4 .

$$
V=D 1 \bigoplus A 1=D 1 \bigoplus A 2 \bigoplus A 1=\cdots=D 1 \bigoplus A n \bigoplus \cdots \bigoplus A 1
$$

Based on the muti-resolution analysis theory, the Mallat algorithm of wavelet decomposition is proposed. The decomposition algorithm can be expressed as the following equation [50].

$$
\left\{\begin{array}{l}
a_{0}=V \\
a_{j}=\sum_{k} h(t-2 k) a_{j-1} \\
d_{j}=\sum_{k} g(t-2 k) a_{j-1}
\end{array}\right.
$$

where the low frequency part/approximation part $A j=\left[a_{1}, a_{2}, \cdots, a_{j}\right]$ is called the j-th layer approximation coefficient, and the high frequency part/ detail part $D j=\left[d_{1}, d_{2}, \cdots, d_{j}\right]$ is called the $\mathrm{j}$-th layer detail coefficient. $H=$ $\left\{h_{j}\right\}_{j \in Z}$ and $G=\left\{g_{j}\right\}_{j \in Z}$ are low-pass filter and high-pass filter respectively.

The signal decomposition process is shown in Figure 4. $A 1, A 2$, and $A 3$ are low frequency part, and $D 1, D 2$, and $D 3$ are high frequency part.

The wavelet coefficients of each layer can be restored to the original sequence length by single reconstruction [50]. The reconstruction algorithm of wavelet coefficients is expressed as follows:

$$
a_{j-1}=\sum_{k} h(t-2 k) a_{j}+\sum_{k} g(t-2 k) d_{j}
$$

Decompose the time series signal into multiple sub-waveforms, and then the prognosis of multiple sub-waveforms can greatly increase the accuracy of signal prediction. The raw voltage waveform of PEMFC is decomposed by wavelet analysis. The low frequency part reflects the overview of the voltage degraded waveform (global degradation trend), and the high frequency part reflects the detail of the voltage degraded waveform (fluctuations and 


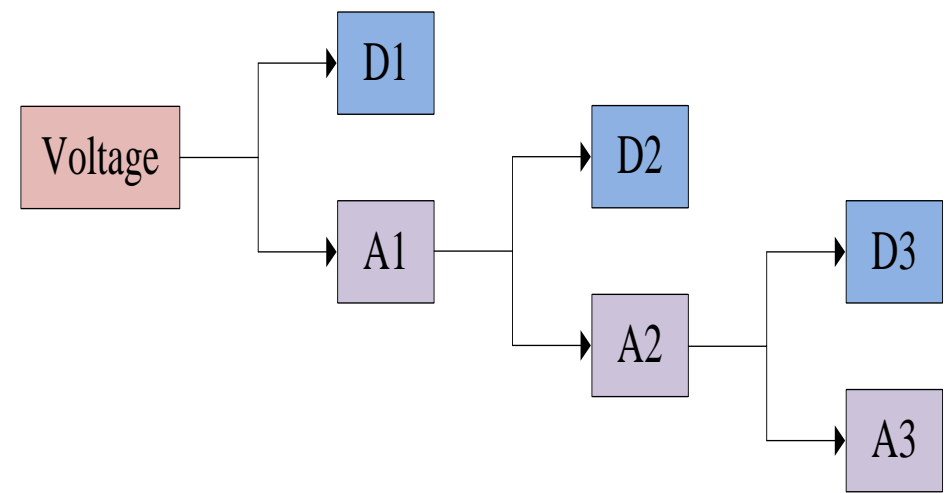

Figure 4: The voltage signal decomposition process based on wavelet basis

recovery phenomena of PEMFC). The prognosis of PEMFC using NARX and wavelet analysis is presented in Fig. 5.

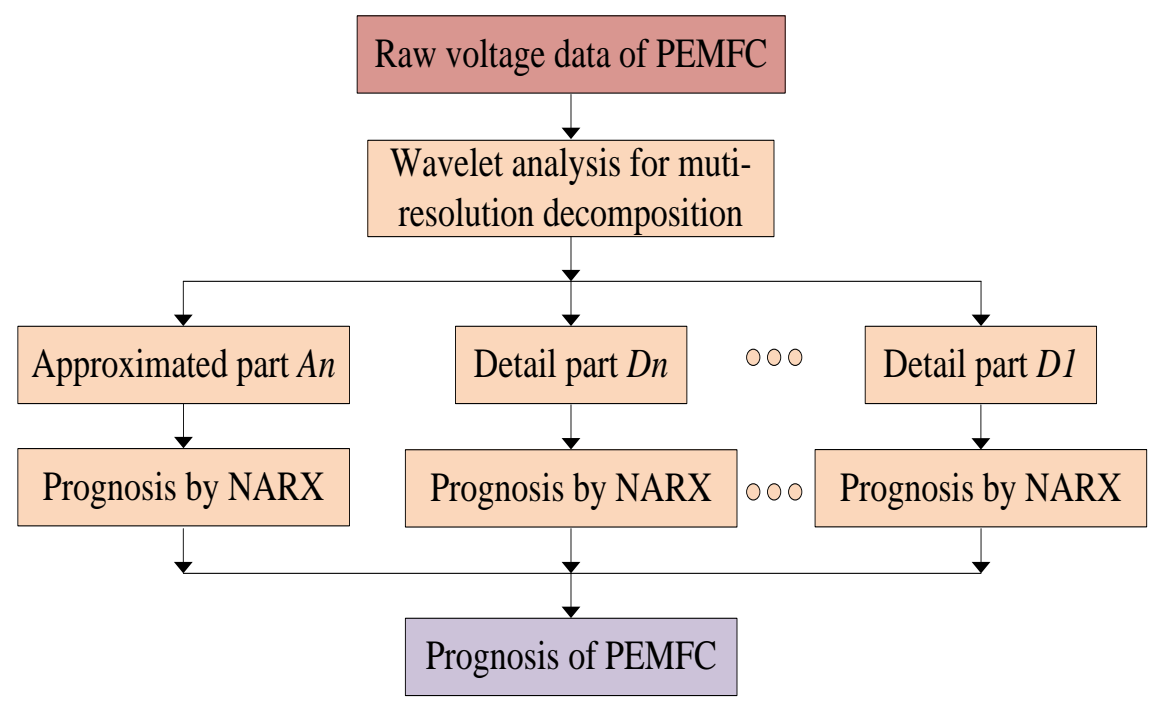

Figure 5: The degradation prognosis of PEMFC based on NARX and wavelet analysis

As shown in Fig. 5, the wavelet analysis is firstly adopted to decompose the raw voltage degraded waveform of PEMFC into multiple sub-waveforms. Then, the prognosis of each sub-waveform is made separately by NARX. Finally, the prognosis of W-NARX is obtained by adding the prognosis of each sub-waveform. 


\section{Results and validation}

\subsection{Setting of the prognosis method}

For NARX, the historical status, load current, relative humidity, temperature, and hydrogen pressure are selected as the input variables. The output voltage of PEMFC is selected as the output variable. The number of maximum delay is selected as 3. The number of neurons in the hidden layer of NARX is chosen as 10. The activation function in hidden layer is set to sigmoid, and the activation function in output layer is set to linear.

For wavelet analysis, the wavelet function type and decomposition scale have a great influence on the prognosis of PEMFC. The order 6 Daubechies wavelet is selected as the wavelet function. The decomposition scale is determined to ensure that the extracted voltage degradation signal is smooth [51]. Considering the accuracy and calculation amount, the number of decomposition scale is selected as 3 for the prognosis of PEMFC in this paper.

In order to evaluate the calculation complexity of different methods, the calculation time is adopted. The commercial computer with an i5-6300 Intel CPU (2.3 GHz clock and 12GB RAM) is used to execute proposed methods. In order to evaluate the accuracy of different methods, Absolute Error (AE), Relative Error (RE), and Mean Square Error (MSE) are used in this paper. Smaller values of AE, RE, and MSE means higher accuracy for the prognosis of PEMFC.

\subsection{The prognosis of PEMFC based on the $W$-NARX and different methods}

In order to analyze the impact of wavelet analysis on degradation prognosis, the prognosis of PEMFC in FCHEV operated under real conditions is made by W-NARX and NARX. 70\% of datasets for PEMFC in FCHEV are applied to learn the degradation trend of PEMFC, and remained datasets are applied to verify the prognosis of PEMFC in FCHEV. The sub-waveform prognosis of PEMFC in FCHEV based on the W-NARX is shown in Fig. 6. The comparison of the prognosis of PEMFC based on the W-NARX and NARX is shown in Fig. 7. The AE of the two methods is shown in Fig. 8.

As shown in Fig. 6, the degradation trend of each wavelet can be accurately learned and forecasted by W-NARX for PEMFC in FCHEV. As shown in Fig. 7, the prognosis of PEMFC based on the W-NARX is better than that of NARX. It shows that W-NARX can accurately learn and forecast PEMFC fluctuations and recovery phenomena. As shown in Fig. 8, the AE of NARX is greater than the AE of W-NARX. The MSE of prognosis of 

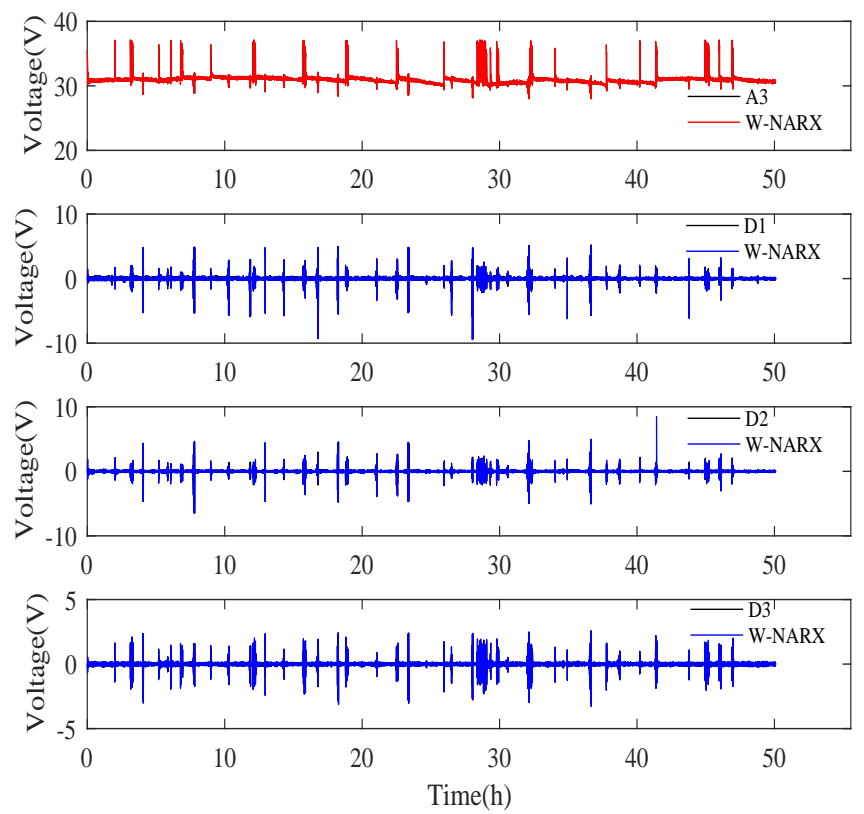

Figure 6: The sub-waveform prognosis of PEMFC in FCHEV under real conditions based on W-NARX

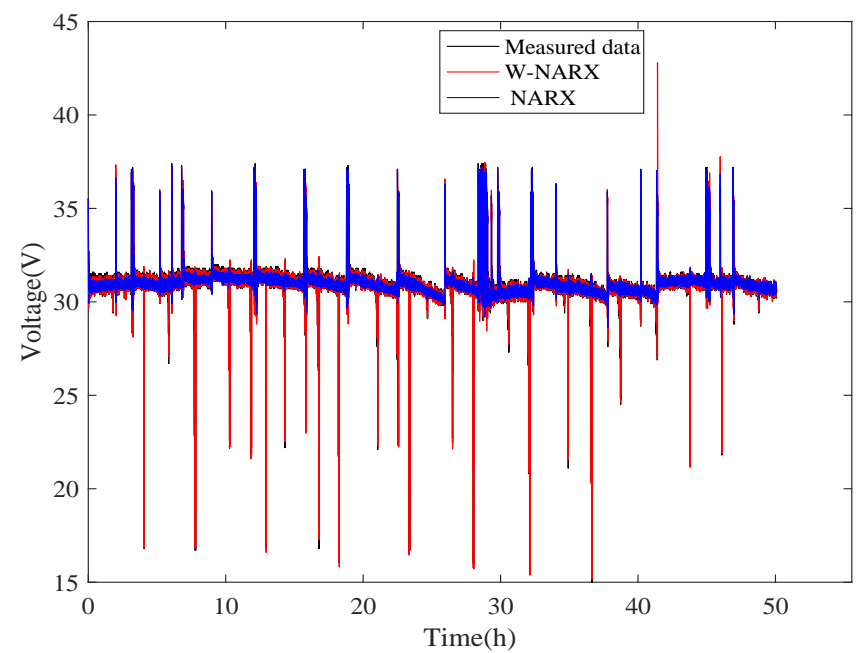

Figure 7: The degradation prognosis of PEMFC in FCHEV under real conditions based on W-NARX and NARX 


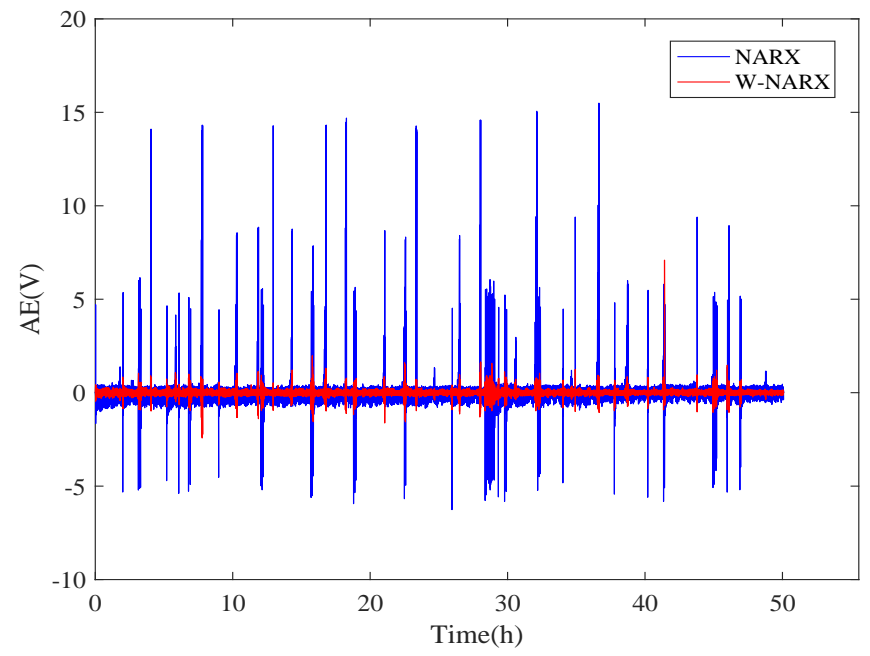

Figure 8: The AE for degradation prognosis of PEMFC in FCHEV under real conditions based on W-NARX and NARX

PEMFC based on the W-NARX is about 0.0059 , and the MSE of prognosis of PEMFC based on the NARX is about 0.0923. The mean RE of prognosis of PEMFC based on the W-NARX is about $0.1359 \%$, and the mean RE of prognosis of PEMFC based on the NARX is about $0.3277 \%$. Compared with the W-NARX, the mean RE of NARX increases by 2.4 times. The reason why the error of W-NARX is lower than the error of NARX is that the fluctuations and recovery phenomena are decomposed into multiple wavelets by wavelet analysis to learn and forecast the degradation of PEMFC. The calculation time of W-NARX is about 918s, and that of NARX is about 232s. Wavelet analysis causes an increase in calculation time. However, compared with the degraded time of the PEMFC, the calculation time of W-NARX is very small. Therefore, W-NARX can be regarded as an appropriate prognosis method to deal with fluctuation and recovery phenomena for PEMFC.

In order to verify the advantages of the proposed method, the prognosis of PEMFC in FCHEV is also made by W-NARX, k-Nearest Neighbors (KNN) algorithm, Decision Tree (DT), and Support Vector Machine (SVM). The comparison of the prognosis of PEMFC based on different methods is shown in Fig. 9. The AE of the prognosis of PEMFC based on the different methods is shown in Fig. 10. The comparison of the accuracy and calculation time of the different methods is shown in Table 4. 


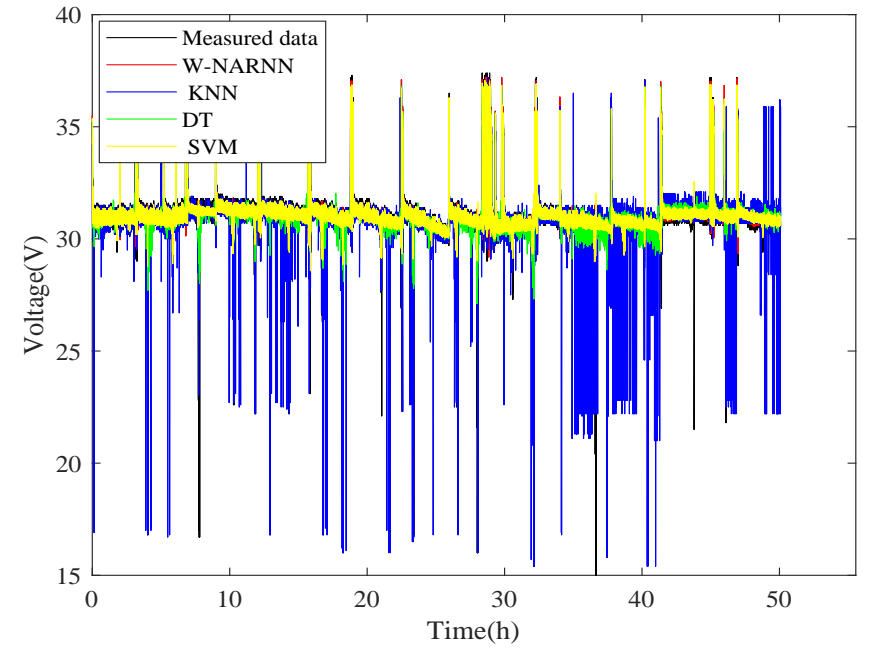

Figure 9: The degradation prognosis of PEMFC in FCHEV under real conditions using different methods

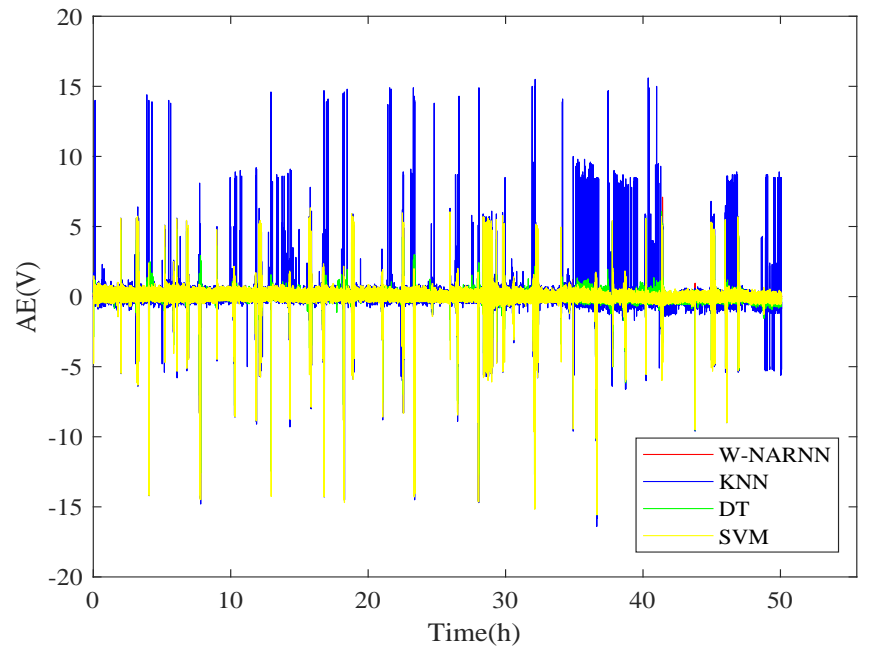

Figure 10: The AE for degradation prognosis of PEMFC in FCHEV under real conditions using different methods 
Table 4: The comparison of the accuracy and calculation time of the different methods

\begin{tabular}{|c|c|c|c|}
\hline Method & MSE & mean RE (\%) & Time (s) \\
\hline KNN & 1.0749 & 1.3161 & 9 \\
\hline DT & 0.1553 & 0.6587 & 39 \\
\hline SVM & 0.1337 & 0.5049 & 1338 \\
\hline W-NARX & 0.0059 & 0.1359 & 918 \\
\hline
\end{tabular}

As shown in Fig. 9, compared with other methods, the prognosis of the proposed W-NARX is closest to the measured data of the PEMFC in FCHEV. As shown in Fig. 10, the AE of the prognosis of PEMFC based on the proposed W-NARX is the smallest. As shown in Table 4, the MSE and mean RE of the proposed W-NARX are the smallest compared with other methods. The proposed W-NARX has higher accuracy than KNN, DT, and SVM.

\subsection{The effect of maximum delay on the prognosis of PEMFC}

The maximum delay has a great influence on the prognosis of PEMFC. For example, the greater the maximum delay, the more historical information of PEMFC the NARX can remember, but it may also cause overfitting. In order to analyze the effect of maximum delay on the accuracy, the prognosis of PEMFC operated under a quasi-dynamic load current is made by W-NARX with different maximum delays. The maximum delay is set to $1,2,3,4,5$, 7,10 , and 15 . In order to reduce measurement errors and calculations, the recorded data is resampled every hour. $70 \%$ of datasets for PEMFC operated under quasi-dynamic load current are applied to learn the degradation trend of PEMFC, and remained datasets are applied to verify the prognosis of PEMFC. The prognosis of PEMFC operated under a quasi-dynamic load current based on the W-NARX with different maximum delays are shown in Fig. 11. The AE of the W-NARX with different maximum delays are shown in Fig. 12. The MSE, mean RE, and calculation time of the W-NARX with different maximum delays are shown in Fig. 13, Fig. 14 and Fig. 15, respectively.

As shown in Fig. 11, the degradation trend of PEMFC operated under a quasi-dynamic load current can be accurately learned and forecasted by WNARX with different maximum delays. As shown in Fig. 12, the maximum 


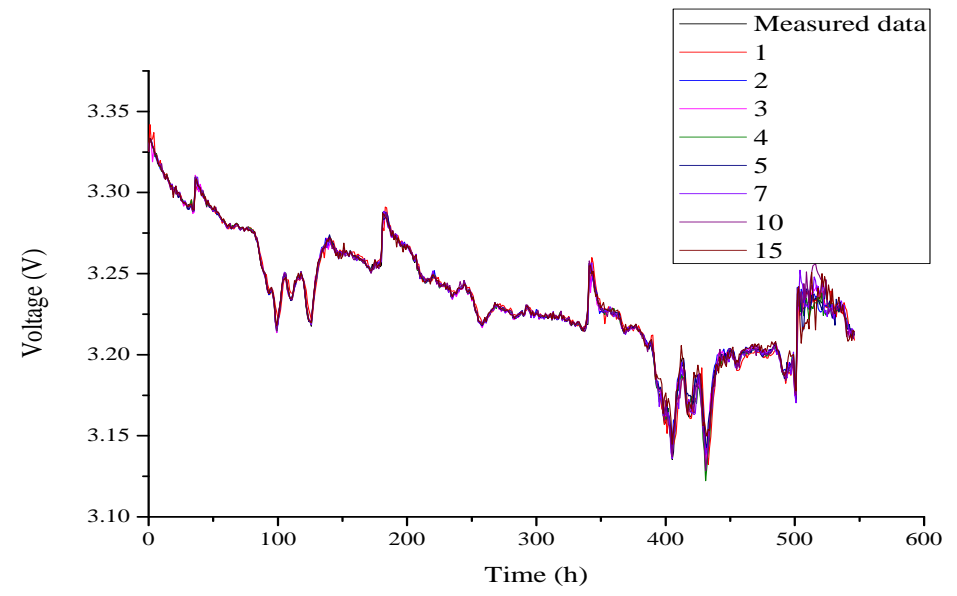

Figure 11: Degradation prognosis of PEMFC under quasi-dynamic load current based on W-NARX with different maximum delays

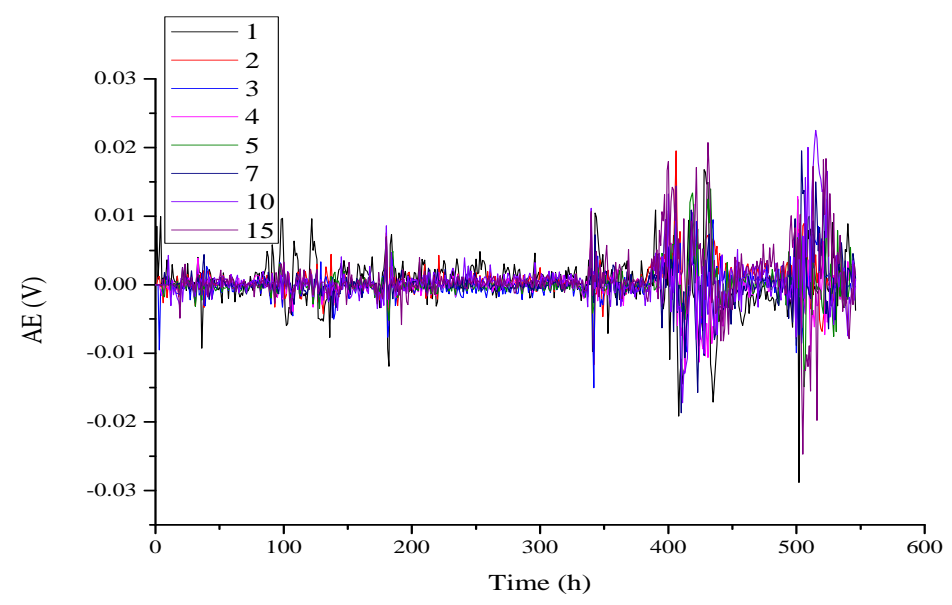

Figure 12: The AE for degradation prognosis of PEMFC under quasi-dynamic load current based on W-NARX with different maximum delays 


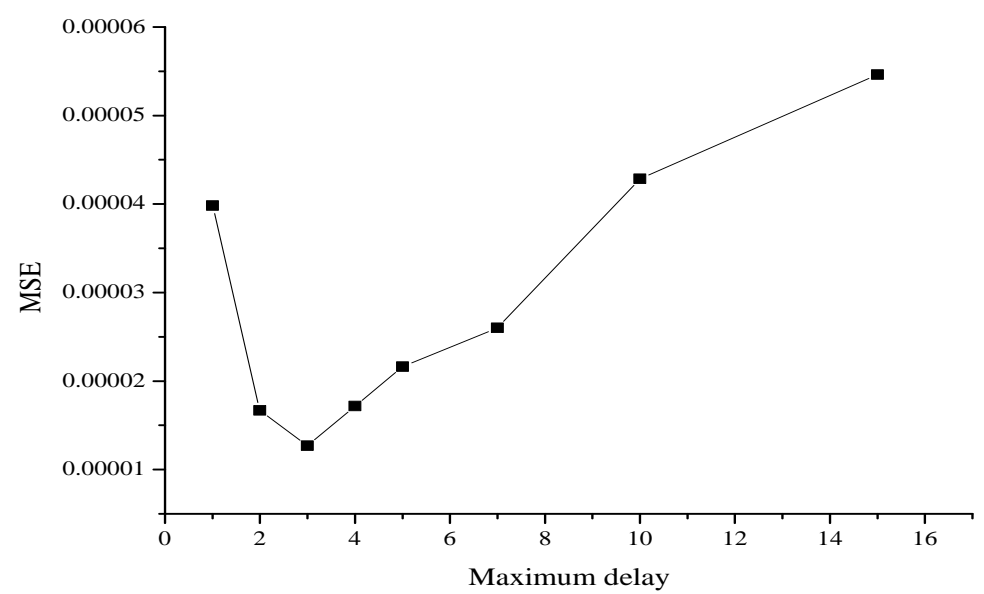

Figure 13: The MSE for degradation prognosis of PEMFC under quasi-dynamic load current based on W-NARX with different maximum delays

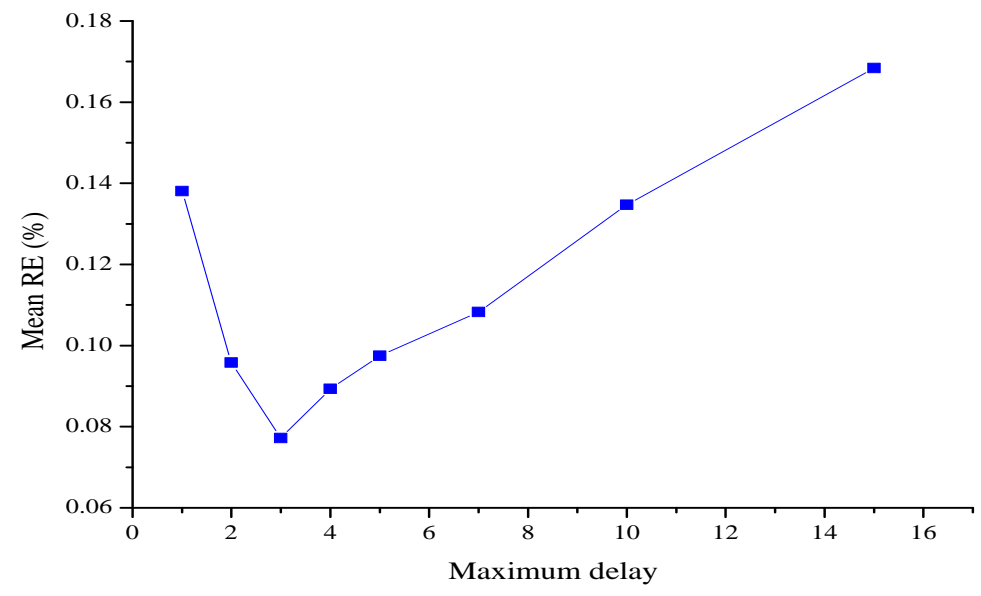

Figure 14: The mean RE for degradation prognosis of PEMFC under quasi-dynamic load current based on W-NARX with different maximum delays 


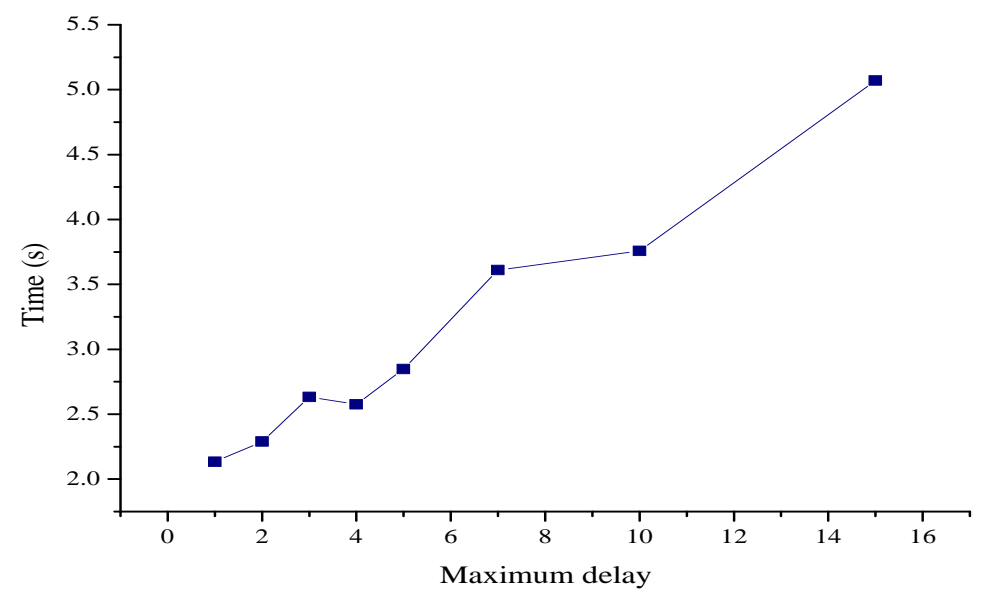

Figure 15: The calculation time for degradation prognosis of PEMFC under quasi-dynamic load current based on W-NARX with different maximum delays

AE of W-NARX with different maximum delays for the prognosis of PEMFC is less than $0.03 \mathrm{~V}$. As shown in Fig. 13 and Fig. 14, when the number of maximum delay is less than 3, the MSE and mean RE are large. Less maximum delay contains less degradation information of PEMFC, which causes an increase in the MSE and mean RE. When the number of maximum delay is more than 3, the MSE and mean RE are also large. Excessive maximum delay may lead to overfitting for the prognosis of PEMFC, which leads to an increase in the MSE and mean RE. As shown in Fig. 15, the calculation time increases as the number of maximum delay increases. This indicates that increasing the maximum delay will increase the amount of calculation. Considering the accuracy and amount of calculation, the number of the maximum delay is chosen as 3 for the prognosis of PEMFC in this paper.

\subsection{The effect of learning data on the prognosis of PEMFC}

The prognosis of PEMFC operated under constant load current is analyzed by W-NARX with different learning data. In order to reduce measurement errors and calculations, the recorded data is resampled every hour. The learning data is respectively chosen as 40\%, 50\%, 60\%, 70\%, 80\%, and $90 \%$ of datasets for PEMFC operated under constant load current, and remained datasets are applied to verify the prognosis of PEMFC. The prognosis of PEMFC operated under constant load current based on the W-NARX with 
$40 \%$ of datasets is shown in Fig. 16. The AE of the W-NARX with $40 \%$ of datasets is shown in Fig. 17. The MSE, mean RE, and calculation time of the W-NARX with different learning data are shown in Fig. 18, Fig. 19 and Fig. 20, respectively.

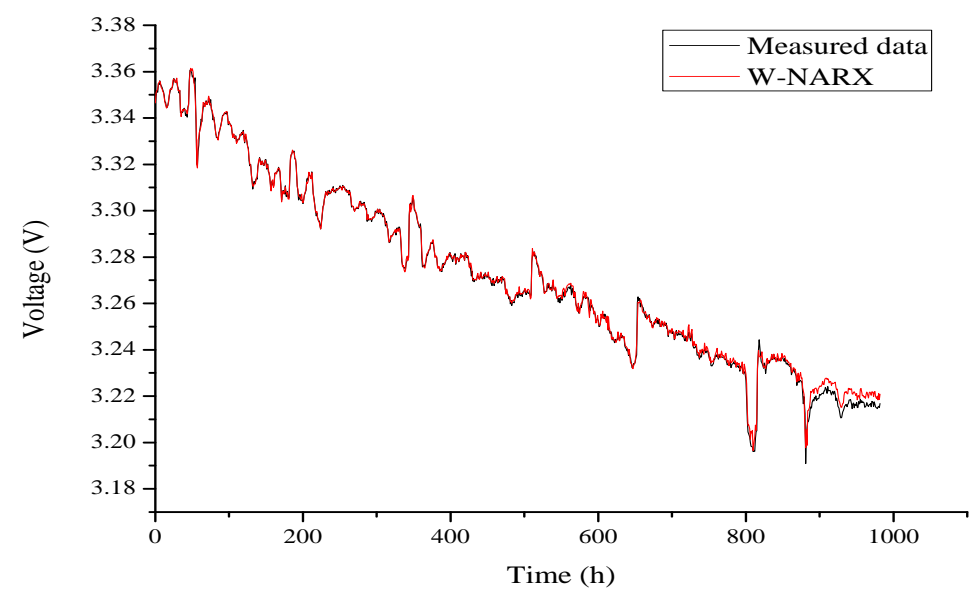

Figure 16: Degradation prognosis of PEMFC under constant load current based on WNARX with $40 \%$ of datasets

As shown in Fig. 16, the degradation trend of PEMFC operated under constant load current can be accurately learned and forecasted by W-NARX with $40 \%$ of datasets. As shown in Fig. 17, the maximum AE of W-NARX with $40 \%$ of datasets for the prognosis of PEMFC is less than $0.01 \mathrm{~V}$. The MSE and mean RE of W-NARX with $40 \%$ of datasets for the prognosis of PEMFC are 0.000006 and $0.055 \%$, respectively. It shows that W-NARX can accurately make the prognosis of PEMFC under the condition of less learning data. As shown in Fig. 18 and Fig. 19, the MSE and mean RE decreases as the learning data increases. As more recorded datasets are used to learn degradation trends of PEMFC, the prognosis of PEMFC based on W-NARX is more accurate, the MSE and mean RE are reduced. This indicates that more learning data can improve the accuracy of the degradation prognosis of PEMFC operated under constant load current. As shown in Fig. 20, the calculation time increases as the learning data increases. The reason for the increased calculation time is that more degradation trends of PEMFC need to be learned in more learning data. 


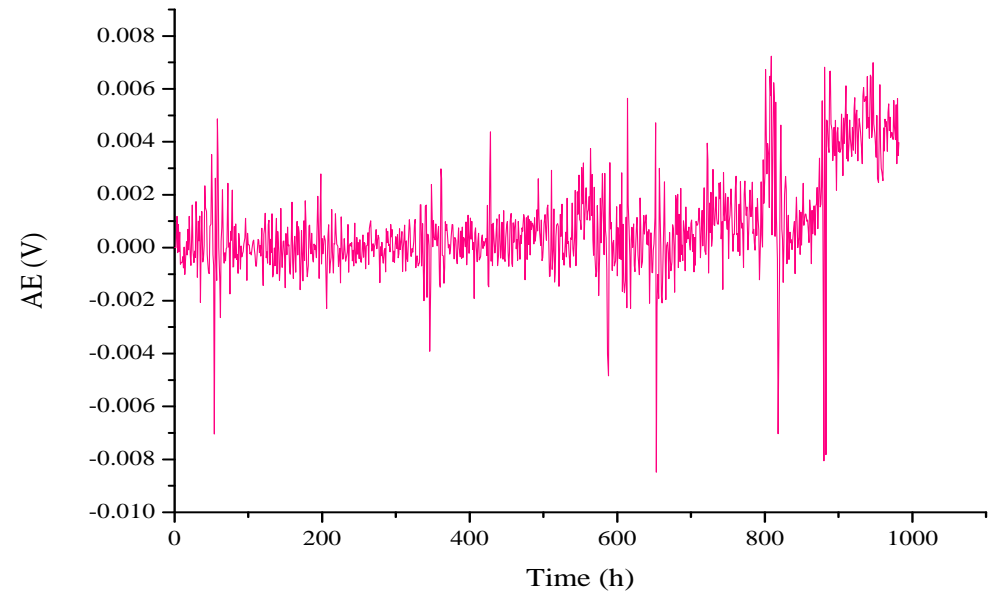

Figure 17: The AE for degradation prognosis of PEMFC under constant load current based on W-NARX with $40 \%$ of datasets

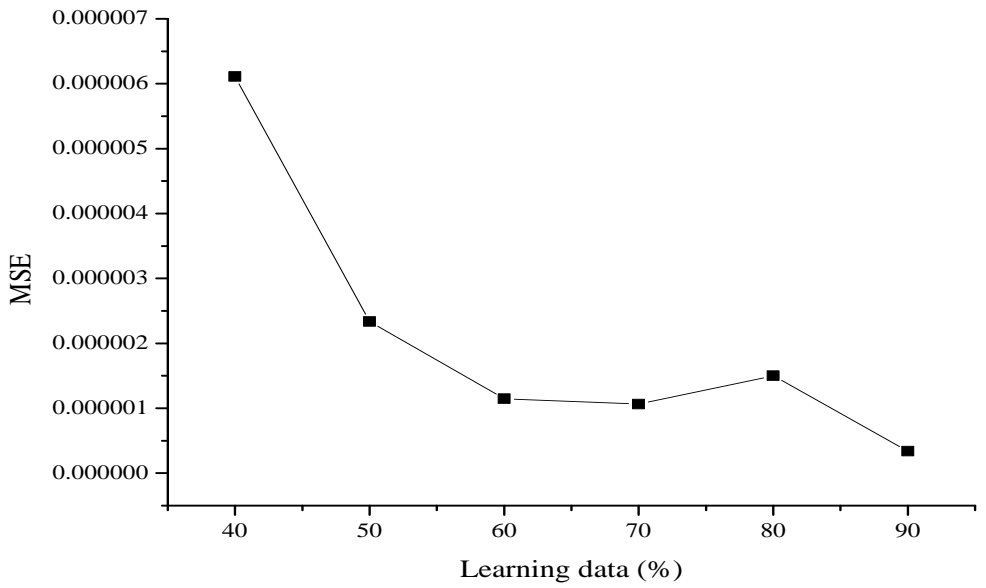

Figure 18: The MSE for degradation prognosis of PEMFC under constant load current based on W-NARX with different learning data 


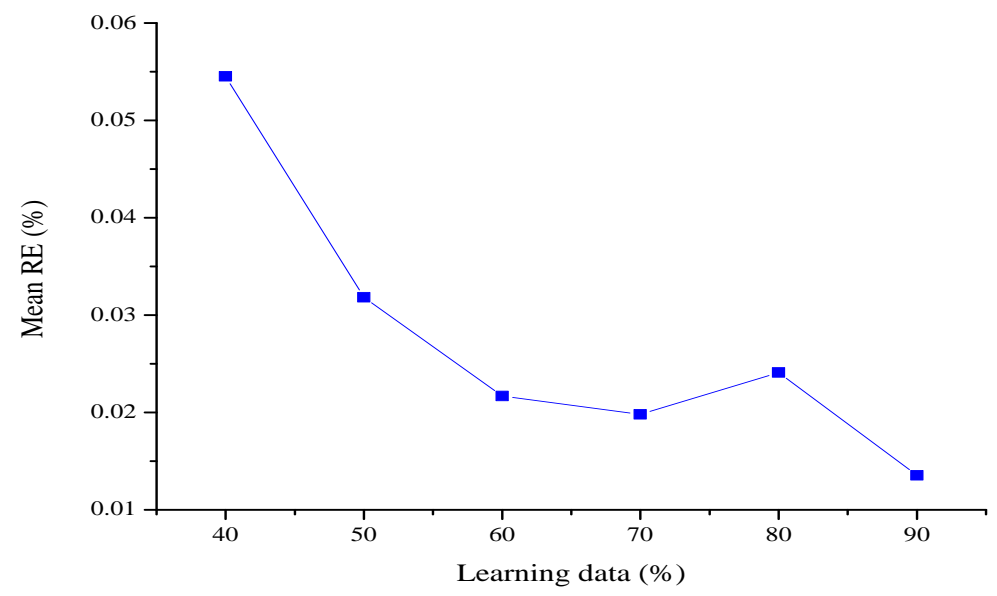

Figure 19: The mean RE for degradation prognosis of PEMFC under constant load current based on W-NARX with different learning data

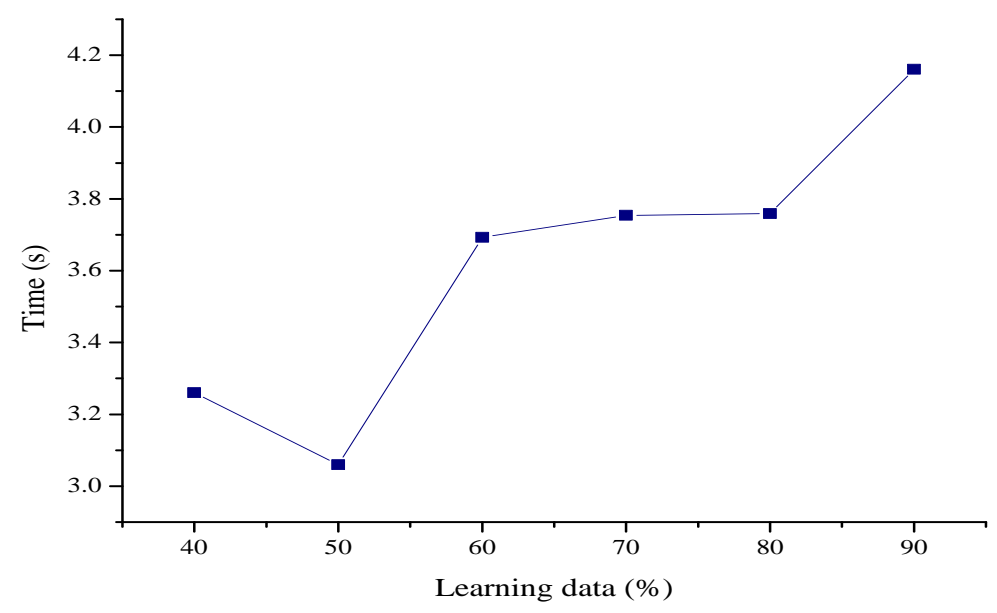

Figure 20: The calculation time for degradation prognosis of PEMFC under constant load current based on W-NARX with different learning data 


\section{Conclusions}

As a kind of renewable and environmentally friendly energy, PEMFC is regarded as a promising technology to solve the energy crisis and environmental crisis. However, the durability caused by degradation seriously limits its commercial application. Degradation prognosis, as the core of prognostics and health management, is regarded as an important tool to improve the durability of PEMFC. This paper presents the degradation prognosis of PEMFC operated under different applications based on wavelet analysis and NARX. The accuracy of the degradation prognosis of PEMFC is validated by three durability tests of PEMFC operated under different applications. The main conclusions of this paper are as follows:

1. Compared with the NARX, the accuracy of W-NARX increases by 2.4 times. The wavelet analysis greatly increases the accuracy of the degradation prognosis of PEMFC based on NARX.

2. Compared with KNN, DT, and SVM, the proposed W-NARX has higher accuracy for the degradation prognosis of PEMFC.

3. The MSE and mean RE are minimal when the maximum delay is 3. Considering the accuracy and amount of calculation, the number of the maximum delay is 3, which is best for the degradation prognosis of PEMFC.

4. The mean RE of W-NARX with $40 \%$ of datasets for the prognosis of PEMFC is less than $0.06 \%$. The W-NARX has a high accuracy of the prognosis of PEMFC under the condition of less learning data. What is more, more learning data helps to improve the accuracy of the degradation prognosis of PEMFC.

The degradation of PEMFC has a great impact on the output performance of PEMFC. The future research work will consider the presented degradation prognosis method combining with energy management theory to improve the output performance and economy for PEMFC in different applications.

\section{Acknowledgment}

The support from Chinese Scholarship Council (CSC), Moby-Post project funded under the Grant Agreement No.256834 by the European Unions seventh Framework program (FP7/2007e2013) for the Fuel Cell and Hydrogen Joint Technology Undertaking (http://mobypostproject.eu/). 


\section{References}

[1] Özçelep, Y., Sevgen, S., Samli, R.. A study on the hydrogen consumption calculation of proton exchange membrane fuel cells for linearly increasing loads: Artificial Neural Networks vs Multiple Linear Regression. Renew Energy 2020;156:570-578.

[2] Prodromidis, G.N., Coutelieris, F.A.. Solid Oxide Fuel Cell systems for electricity generation: An optimization prospect. Renew Energy 2020;146:38-43.

[3] Herr, N., Nicod, J.M., Varnier, C., Jardin, L., Sorrentino, A., Hissel, D., Péra, M.C.. Decision process to manage useful life of multi-stacks fuel cell systems under service constraint. Renew Energy 2017;105:590600.

[4] Becherif, M., Hissel, D., Gaagat, S., Wack, M.. Electrical equivalent model of a proton exchange membrane fuel cell with experimental validation. Renew Energy 2011;36(10):2582-2588.

[5] Matraji, I., Laghrouche, S., Wack, M.. Cascade control of the motocompressor of a PEM fuel cell via second order sliding mode. In: 2011 50th IEEE Conf. Decis. Control Eur. Control Conf. 2011, p. 633-638.

[6] Laghrouche, S., Harmouche, M., Ahmed, F.S., Chitour, Y.. Control of PEMFC air-feed system using Lyapunov-based robust and adaptive higher order sliding mode control. IEEE Trans Control Syst Technol 2014;23(4):1594-1601.

[7] Boulon, L., Agbossou, K., Hissel, D., Sicard, P., Bouscayrol, A., Péra, M.C.. A macroscopic PEM fuel cell model including water phenomena for vehicle simulation. Renew Energy 2012;46:81-91.

[8] Mohammadi, M., Mehdipour-Ataei, S.. Durable sulfonated partially fluorinated polysulfones as membrane for PEM fuel cell. Renew Energy 2020;158:421-430.

[9] Alipour MoghadamEsfahani, R., Vankova, S.K., Easton, E.B., Ebralidze, I.I., Specchia, S.. A hybrid Pt/NbO/CNTs catalyst with high activity and durability for oxygen reduction reaction in PEMFC. Renewable Energy 2020;154:913-924. 
[10] Wang, H., Gaillard, A., Hissel, D.. A review of DC/DC converter-based electrochemical impedance spectroscopy for fuel cell electric vehicles. Renew Energy 2019;141:124-138.

[11] Yi, P., Li, X., Yao, L., Fan, F., Peng, L., Lai, X.. A lifetime prediction model for coated metallic bipolar plates in proton exchange membrane fuel cells. Energy Convers Manag 2019;183:65-72.

[12] Jouin, M., Bressel, M., Morando, S., Gouriveau, R., Hissel, D., Péra, M.C., Zerhouni, N., Jemei, S., Hilairet, M., Ould Bouamama, B.. Estimating the end-of-life of PEM fuel cells: Guidelines and metrics. Appl Energy 2016;177:87-97.

[13] Jouin, M., Gouriveau, R., Hissel, D., Péra, M.C., Zerhouni, N.. Prognostics and Health Management of PEMFC State of the art and remaining challenges. Int J Hydrogen Energy 2013;38(35):15307-15317.

[14] Vichard, L., Petrone, R., Harel, F., Ravey, A., Venet, P., Hissel, D.. Long term durability test of open-cathode fuel cell system under actual operating conditions. Energy Convers Manag 2020;212:112813.

[15] Sutharssan, T., Montalvao, D., Chen, Y.K., Wang, W.C., Pisac, C., Elemara, H.. A review on prognostics and health monitoring of proton exchange membrane fuel cell. Renew Sustain Energy Rev 2017;75:440450.

[16] Jouin, M., Gouriveau, R., Hissel, D., Péra, M.C., Zerhouni, N.. Degradations analysis and aging modeling for health assessment and prognostics of PEMFC. Reliab Eng Syst Saf 2016;148:78-95.

[17] Liu, H., Chen, J., Hissel, D., Lu, J., Hou, M., Shao, Z.. Prognostics methods and degradation indexes of proton exchange membrane fuel cells: A review. Renew Sustain Energy Rev 2020;123:109721.

[18] Bressel, M., Hilairet, M., Hissel, D., Ould Bouamama, B.. Extended Kalman Filter for prognostic of Proton Exchange Membrane Fuel Cell. Appl Energy 2016;164:220-227.

[19] Jouin, M., Gouriveau, R., Hissel, D., Péra, M.C., Zerhouni, N.. Prognostics of PEM fuel cell in a particle filtering framework. Int $\mathrm{J}$ Hydrogen Energy 2014;39(1):481-494. 
[20] Bressel, M., Hilairet, M., Hissel, D., Bouamama, B.O.. Remaining useful life prediction and uncertainty quantification of proton exchange membrane fuel cell under variable load. IEEE Trans Ind Electron 2016;63(4):2569-2577.

[21] Chen, J., Zhou, D., Lyu, C., Lu, C.. A novel health indicator for PEMFC state of health estimation and remaining useful life prediction. Int J Hydrogen Energy 2017;42(31):20230-20238.

[22] Han, I.S., Park, S.K., Chung, C.B.. Modeling and operation optimization of a proton exchange membrane fuel cell system for maximum efficiency. Energy Convers Manag 2016;113:52-65.

[23] Wu, Y., Breaz, E., Gao, F., Paire, D., Miraoui, A.. Nonlinear performance degradation prediction of proton exchange membrane fuel cells using relevance vector machine. IEEE Trans Energy Convers 2016;31(4):1570-1582.

[24] Morando, S., Jemei, S., Hissel, D., Gouriveau, R., Zerhouni, N.. Proton exchange membrane fuel cell ageing forecasting algorithm based on Echo State Network. Int J Hydrogen Energy 2017;42(2):1472-1480.

[25] Wang, F.K., Mamo, T., Cheng, X.B.. Bi-directional long shortterm memory recurrent neural network with attention for stack voltage degradation from proton exchange membrane fuel cells. J Power Sources 2020;461:228170.

[26] Wu, Y., Breaz, E., Gao, F., Miraoui, A.. A modified relevance vector machine for PEM fuel-cell stack aging prediction. IEEE Trans Ind Appl 2016;52(3):2573-2581.

[27] Silva, R., Gouriveau, R., Jemeï, S., Hissel, D., Boulon, L., Agbossou, K., Yousfi Steiner, N.. Proton exchange membrane fuel cell degradation prediction based on Adaptive Neuro-Fuzzy Inference Systems. Int J Hydrogen Energy 2014;39(21):11128-11144.

[28] Liu, J., Li, Q., Chen, W., Yan, Y., Qiu, Y., Cao, T.. Remaining useful life prediction of PEMFC based on long short-term memory recurrent neural networks. Int J Hydrogen Energy 2018;44(11):5470-5480. 
[29] Cheng, Y., Zerhouni, N., Lu, C.. A hybrid remaining useful life prognostic method for proton exchange membrane fuel cell. Int J Hydrogen Energy 2018;43(27):12314-12327.

[30] Zhou, D., Al-Durra, A., Gao, F., Ravey, A., Matraji, I., Godoy Simões, M.. Online energy management strategy of fuel cell hybrid electric vehicles based on data fusion approach. J Power Sources 2017;366(September 2018):278-291.

[31] Liu, H., Chen, J., Hissel, D., Su, H.. Remaining useful life estimation for proton exchange membrane fuel cells using a hybrid method. Appl Energy 2019;237:910-919.

[32] Duan, J., He, Y., Zhu, H., Qin, G., Wei, W.. Research progress on performance of fuel cell system utilized in vehicle. Int J Hydrogen Energy 2019;44(11):5530-5537.

[33] Park, J., Oh, H., Ha, T., Lee, Y.I., Min, K.. A review of the gas diffusion layer in proton exchange membrane fuel cells: Durability and degradation. Appl Energy 2015;155:866-880.

[34] Kannan, V., Xue, H., Raman, K.A., Chen, J., Fisher, A., Birgersson, E.. Quantifying operating uncertainties of a PEMFC Monte Carlomachine learning based approach. Renew Energy 2020;158:343-359.

[35] Chen, H., Zhao, X., Zhang, T., Pei, P.. The reactant starvation of the proton exchange membrane fuel cells for vehicular applications: A review. Energy Convers Manag 2019;182:282-298.

[36] Mandal, P., Hong, B.K., Oh, J.G., Litster, S.. Understanding the voltage reversal behavior of automotive fuel cells. J Power Sources 2018;397:397-404.

[37] Cao, T.F., Lin, H., Chen, L., He, Y.L., Tao, W.Q.. Numerical investigation of the coupled water and thermal management in PEM fuel cell. Appl Energy 2013;112:1115-1125.

[38] Hosseinzadeh, E., Rokni, M., Rabbani, A., Mortensen, H.H.. Thermal and water management of low temperature Proton Exchange Membrane Fuel Cell in fork-lift truck power system. Appl Energy 2013;104:434-444. 
[39] Chen, K., Laghrouche, S., Djerdir, A.. Degradation prediction of proton exchange membrane fuel cell based on grey neural network model and particle swarm optimization. Energy Convers Manag 2019;195:810818.

[40] Hu, Z., Xu, L., Li, J., Ouyang, M., Song, Z., Huang, H.. A reconstructed fuel cell life-prediction model for a fuel cell hybrid city bus. Energy Convers Manag 2018;156:723-732.

[41] Gazdzick, P., Mitzel, J., Garcia Sanchez, D., Schulze, M., Friedrich, K.A.. Evaluation of reversible and irreversible degradation rates of polymer electrolyte membrane fuel cells tested in automotive conditions. J Power Sources 2016;327:86-95.

[42] Jouin, M., Gouriveau, R., Hissel, D., Péra, M.C., Zerhouni, N.. Joint particle filters prognostics for proton exchange membrane fuel cell power prediction at constant current solicitation. IEEE Trans Reliab 2016;65(1):336-349.

[43] Pei, P., Jia, X., Xu, H., Li, P., Wu, Z., Li, Y., Ren, P., Chen, D., Huang, S.. The recovery mechanism of proton exchange membrane fuel cell in micro-current operation. Appl Energy 2018;226:1-9.

[44] Wang, F., Yang, D., Li, B., Zhang, H., Hao, C., Chang, F., Ma, J.. Investigation of the recoverable degradation of PEM fuel cell operated under drive cycle and different humidities. Int J Hydrogen Energy 2014;39(26):14441-14447.

[45] Chen, K., Laghrouche, S., Djerdir, A.. Fuel cell health prognosis using Unscented Kalman Filter: Postal fuel cell electric vehicles case study. Int J Hydrogen Energy 2019;44(3):1930-1939.

[46] Mohammadi, A., Djerdir, A., Steiner, N.Y., Bouquain, D., Khaburi, D.. Diagnosis of PEMFC for automotive application. In: IYCE 2015 Proc. 2015 5th Int. Youth Conf. Energy. IEEE. ISBN 1467371726; 2015, p. 1-6.

[47] Gouriveau, R., Hilairet, M., Hissel, D., Jemei, S., Jouin, M., Lechartier, E., Morando, S., Pahon, E., Pera, M.C., Zerhouni, N.. IEEE PHM 2014 data challenge: Outline, experiments, scoring of results, winners. IEEE 2014 PHM Challenge, Tech Rep 2014;. 
[48] Menezes Jr, J.M.P., Barreto, G.A.. Long-term time series prediction with the NARX network: An empirical evaluation. Neurocomputing 2008;71(16-18):3335-3343.

[49] Huo, F., Poo, A.N.. Nonlinear autoregressive network with exogenous inputs based contour error reduction in $\mathrm{CNC}$ machines. Int $\mathrm{J}$ Mach Tools Manuf 2013;67:45-52.

[50] Mallat, S.G.. Multifrequency channel decompositions of images and wavelet models. IEEE Transactions on Acoustics, Speech, and Signal Processing 1989;37(12):2091-2110.

[51] Misiti, M., Misiti, Y., Oppenheim, G., Poggi, J.M.. Wavelets and their Applications. John Wiley \& Sons; 2013. ISBN 1118613597. 